Review began $08 / 08 / 2021$

Review ended 08/19/2021

Published 08/30/202

(๑) Copyright 2021

Hannan et al. This is an open access article distributed under the terms of the Creative Commons Attribution License CC-BY 4.0. which permits unrestricted use, distribution, and reproduction in any medium, provided the original author and source are credited

\section{Drug Utilization Study of Antidiabetic Drugs in Patients Attending Geriatric Outpatient Department at a Tertiary Care Hospital}

\author{
Abdul Hannan ${ }^{1}$, Shyamal R. Sinha ${ }^{1}$, Mohammad Arfat Ganiyani ${ }^{1,2}{ }^{\text {, Manas Pustake }}{ }^{2,1}$
}

1. Department of Pharmacology, Grant Government Medical College and Sir Jamshedjee Jeejeebhoy Group of Hospitals, Mumbai, IND 2. Department of Internal Medicine, Grant Government Medical College and Sir Jamshedjee Jeejeebhoy Group of Hospitals, Mumbai, IND

Corresponding author: Mohammad Arfat Ganiyani, mdarfatganiyani720@gmail.com

\section{Abstract \\ Introduction}

Diabetes has increased in prevalence from 108 million individuals in 1980 to 463 million individuals in 2021. As people's life expectancies have risen, it's become increasingly necessary to be worried about diseases that affect the elderly. To focus and manage these diseases effectively, the illumination of current knowledge about the pattern of anti-diabetic drug utilization in the elderly is important. As a result, it is necessary to evaluate the pattern of anti-diabetic medication use among diabetes patients of the geriatric age group and determine if there is room for improvement in light of current knowledge. With this information, we intend to provide feedback and suggestions for the health care providers. This research aimed to study and analyze the drug utilization of antidiabetic medications in patients attending the geriatric outpatient department.

\section{Methods}

The data of 600 patients visiting the geriatric outpatient department from January 1, 2016 to September 30, 2017 were collected from the electronic medical record (EMR) database. The protocol was designed using Strengthening the Reporting of Observational Studies in Epidemiology (STROBE) guidelines. Subjects were grouped according to gender, age, drug combination use, and underlying co-morbidities. Indicators of drug usage and the total number of drugs prescribed and prescription patterns were analyzed. Then, the recorded data were classified according to the anatomical therapeutic chemical (ATC) - daily defined dose (DDD) classification. Prescribed daily dose (PDD) values and PDD/DDD ratio of antidiabetic drugs prescribed to a sample of patients $(n=600)$ were calculated. Cost analysis of the prescribed drugs was analyzed and the cost index for each drug is described.

\section{Results}

A total of 600 diabetic patients (286 males) were recruited in the study. In the study, the average age of participants was $69.30 \pm 11.34$ years. The most common comorbidity associated with diabetes mellitus (DM) was hypertension followed by hypertension along with chronic heart disease. Glibenclamide and pioglitazone (thiazolidenediones) had PDD/DDD ratio equal to 1. The ratios for glimepiride (sulfonylurea), metformin (biguanides), sitagliptin (sodium-glucose cotransporter 2 inhibitor), insulin glargine, insulin lispro, insulin aspart, were $1.85,1.29,1.66,1.63,1.42$, and 1.21 , respectively, whereas the premixed insulin had a ratio of 0.83 . The average cost per prescription was USD 3.36 and around $87.72 \%$ of the cost per prescription was due to the prescribed antidiabetics. Metformin + glibenclamide was the most commonly prescribed combination followed by metformin + glimepiride.

\section{Conclusion}

On the whole, the principles of rational prescription were followed in accordance with the different WHO drug usage indicators. Many of the drugs prescribed by generic name were supplied from hospital pharmacy thus reducing the burden to some extent.

Categories: Internal Medicine, Public Health, Therapeutics

Keywords: diabetes, anti-diabetic medications, daily defined dose, prescribed daily dose, pdd/ddd ratio

\section{Introduction}

Diabetes mellitus (DM) is becoming an important public health problem in developing countries, especially in India. The number of people with diabetes has risen from 108 million in 1980 to 463 million adults in 2021 [1]. Type 2 DM is very common among the elderly [2]. Various classes of anti-diabetic drugs including insulin and oral hypoglycemic agents (OHAs) are currently being used in the treatment of diabetes, which acts by various mechanisms to reduce the blood glucose levels in order to maintain optimal glycemic control. The utilization study of these medications is important in clinical practice because it serves as the foundation for implementing changes to drug dispensing policies at the local and national levels. Irrational drug use can lead to adverse outcomes including an increase in the risk of hypoglycemia, a decline in 
medication adherence, the risk of drug-drug interactions, all of which can invariably lead to an increased risk of hospitalization, fatality rate, and healthcare costs [3]. Drug Utilization Research (DUR) was defined by the WHO in 1977 as "The study of the marketing, distribution, prescription, and use of drugs in a society, with special emphasis on the resulting medical, social and economic implications" [4]. The main implication of such studies is to promote rational medication usage. Drug utilization studies help in developing strategies to utilize health resources most efficiently, they are particularly needed in a developing economy like India where age-standardized disability-adjusted life-years (DALY) for diabetes is increased by 39.6\% since 1990, the largest rise among major non-communicable diseases [5].

World Health Organization (WHO) has projected that diabetes will be the seventh leading cause of death in 2030 in the world [6]. With the enhancement of diagnostic and treatment facilities, with better healthcare facilities and awareness, we now have a growing population of elderly people [7]. As this demographic group expands, the disease burden increases as well, putting an additional strain on an already overloaded healthcare system. Proper evaluation of their problems, correct diagnosis, and suitable treatment are the key factors in reducing this disease burden. This aids in the improvement in the patients' quality of life, which is extremely important.

Without knowledge of how drugs are being prescribed and used, it is difficult to suggest measures to change prescribing habits for the better [8]. It, therefore, becomes important to assess the pattern of the usage of anti-diabetic drugs among the diabetic patients of the geriatric age group and to see to what extent there may be scope for improvement in the light of current knowledge. A previous drug utilization study for OHA done in India was by Sultana et al. in 2010 [8,9]. In their study, the majority of type 2 diabetic patients were treated with multiple antidiabetic drug therapy. The most commonly prescribed antidiabetic drug class was biguanides followed by sulphonylureas, thiazolidinediones, insulin, and alpha-glucosidase inhibitors. They have reported that the metformin was most commonly prescribed monotherapy followed by insulin. They had emphasized the need for patient education for promoting rational use of medications to promote drug adherence. This study has also recommended drug utilization studies should be carried out in a large population and at different locations in India so that the utilization patterns may be compared and diabetes management improved, thus suggesting a need for a longer-term study on a larger sample size [9]. Although many similar studies were done previously, no studies particularly were done in the geriatric population. We plan to use these data to offer feedback and suggestions to healthcare professionals. Thus, this study was designed.

\section{Materials And Methods}

\section{Setting}

The study was done in Geriatric Outpatient Department, Sir JJ Group of Hospitals, Mumbai, one of the largest government tertiary health centre in Western India.

\section{Study design and ethical considerations}

A retrospective drug utilization study was conducted after the approval of the institutional ethics committee (IEC Document number: IEC/Pharm/445/2014). The guidelines for Strengthening the Reporting of Observational Studies in Epidemiology (STROBE) were used in the designing of the protocol and the manuscript [10].

\section{Selection criteria}

Inclusion Criteria

Prescriptions of both the sexes of the geriatric population (defined as age $>60$ years) diagnosed with DM since at least five years and started on either OHA or insulin that were selected for the study.

\section{Exclusion Criteria}

Patients with other coexistent causes of hyperglycemia (e.g., Cushing's syndrome, pancreatic cancer, or hormone-secreting tumors) were excluded from the study.

\section{Sample size}

Six hundred prescriptions were assessed from medical databases/registries as per WHO standards [8] for performing retrospective drug utilization studies.

\section{Study procedure}

The data of patients visiting the geriatric outpatient department (OPD) from January 1, 2016 to September 30, 2017 were collected from the electronic medical record (EMR) database, avoiding Hawthorne's bias, and was documented in a systematic case record form. During the period of the study, the sample frame was set at three prescriptions a day, three days a week. Three prescriptions were chosen as follows: on day one, all three prescriptions were picked at the start of the day; on day 2, three prescriptions were picked in the middle of the day; on day 3, three prescriptions were selected at the end of the day, and so on. In the event of an OPD holiday, the prescriptions for that day were allocated to the next working day. This method was 


\section{Cureus}

adopted because of three fixed geriatric OPD days per week in our hospital and also to eliminate potential bias.

\section{Data collection and analysis}

Data were collected relating to participant demographics and clinical characteristics. The demographic data collected included: medical records department number, gender, age, smoking status, marital status, education level, employment status, income, and occupation. The clinical characteristics data obtained were: length of time since diagnosis with DM, body mass index (BMI), and any relevant medical history or co-morbidities in the records, of any diabetes complications. Prescription details like date, number of drugs, names of individual drugs (generic/brand), any fixed-dose combination (FDC) prescribed, and whether the prescribed drugs were available from the hospital pharmacy, dose, dosage form, dosing schedule, and duration of treatment were all recorded. The medicines that were dispensed by the hospital pharmacy were documented. Those who were not distributed from hospital pharmacies were considered to be purchased from outside pharmacy outlets.

\section{Data analysis}

Prescription patterns were assessed as defined by the World Health Organization-International Network of Rational Use of Drugs (WHO-INRUD) drug usage indicators [11]. The prescription medications were categorized using the anatomical therapeutic chemical (ATC) - defined daily dose (DDD) system [12]. The Prescribed Daily Dose (PDD) was derived by averaging the daily dosage of the antidiabetic medicines [13]. The PDD/DDD ratio was then computed by using appropriate values.

\section{Cost analysis}

The cost of medications prescribed from the hospital schedule was calculated based on the rate contract available in the hospital drug store. The cost of the drugs prescribed from pharmacies outside the hospital was obtained from the Drug Index (DI): February 2017 [14]. The cost parameters calculated were average total cost per prescription, percentage of average cost due to antidiabetic drugs average cost borne by the hospital, average cost borne by the patient. We estimated the price per 10 tablets/capsules (minimum and maximum, as per DI), average monthly cost (minimum and maximum), which was equal to (PDD/dose per tablet) $\times$ price per 10 tablets $\times 3$ and cost index $(\mathrm{CI})$ (maximum price/minimum price) for pharmaceuticals prescribed from outside pharmacies. The cost of each drug was modeled in the USD.

\section{Statistical analysis}

The descriptive data were reported in percentages for categorical variables and mean $(\backslash \mathrm{pm} \backslash) \mathrm{SD}$ for continuous variables. All statistical calculations were done using IBM Statistical Package for the Social Sciences (SPSS) version 24 (IBM Corp., Armonk, NY).

\section{Results}

\section{Demographic characteristics}

A total of 600 diabetic patients were recruited in this study, out of which 286 (47.66\%) were males and 314 (52.33\%) were females. In the study, the average age of the male population was $69.75 \pm 11.08$ years and that of the female population was $68.85 \pm 11.34$ years. Patients were observed to be mostly in the $61-70$ years age range (70\%) followed by $71-80$ years $(24.5 \%)$.

\section{Comorbidities associated with DM}

The most common comorbidity associated with DM was hypertension (56.33\%) followed by hypertension along with chronic heart disease (23.16\%); details of which are presented in Figure 1. 


\section{Cureus}

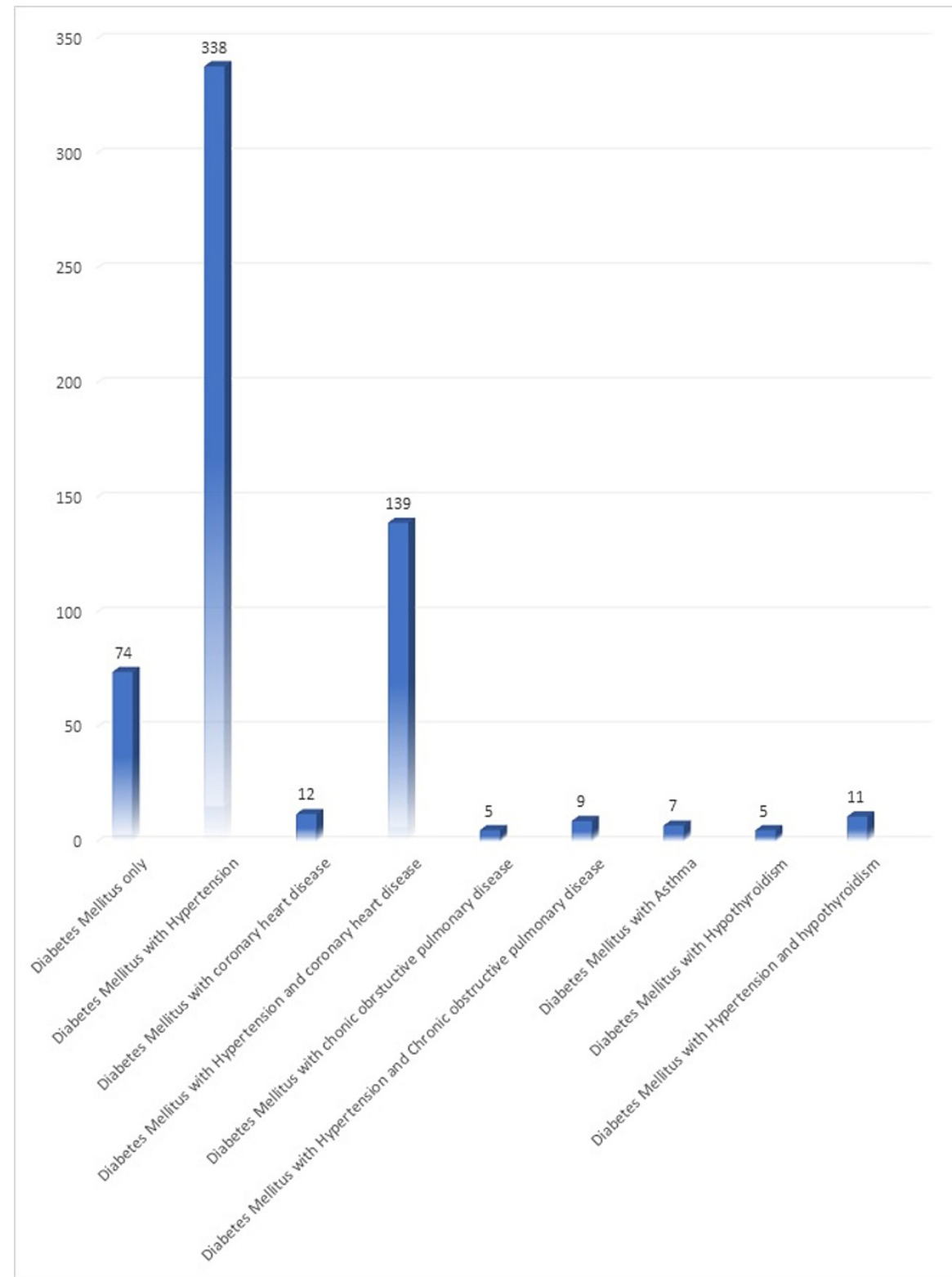

FIGURE 1: Percentage distribution of diabetes mellitus and comorbidities $(n=600)$

\section{Utilization of anti-diabetic drugs}

Metformin (biguanide antidiabetic class) was the single most commonly prescribed antidiabetic agent (585 (97.5\%) of 600 study participants). It was followed by the sulfonylureas group, which was used by $53.66 \%$ of patients. Glibenclamide was the most commonly prescribed sulfonylurea in 263 (43.83\%) patients followed by glimepiride in 59 patients $(9.83 \%)$. The percentage distribution of antidiabetic drugs is shown in Table 1 . 


\section{Cureus}

\begin{tabular}{|c|c|c|}
\hline Drug class & Drug & Number of patients (\%) \\
\hline Biguanides & Metformin & 585 (97.5) \\
\hline \multirow{2}{*}{ Sulfonylureas } & Glibenclamide & $263(43.83)$ \\
\hline & Glimepiride & $59(9.83)$ \\
\hline Alpha-glucosidase inhibitor & Voglibose & $42(7.0)$ \\
\hline DPP-4 inhibitor & Sitagliptin & $9(1.5)$ \\
\hline TZD & Pioglitazone & $27(4.5)$ \\
\hline \multirow{4}{*}{ Insulin } & Premixed insulin (regular insulin + NPH) & $32(5.33)$ \\
\hline & Insulin glargine & $10(1.66)$ \\
\hline & Insulin aspart & $8(1.33)$ \\
\hline & Insulin Lispro & $2(0.33)$ \\
\hline
\end{tabular}

TABLE 1: Percentage distribution of antidiabetic drugs in the patients studied DPP-4: dipeptidyl peptidase-4, TZD: thiazolidinedione, NPH: neutral protamine Hagedorn.

Insulin was prescribed to 42 patients (7\%) out of 600 in three types of regimens. The most often prescribed regimen (regular insulin + NPH insulin) was split mixed in 32 patients $(76.19 \%)$, followed by the basal-bolus regimen (glargine + aspart) in 8 patients (19.04\%). Figure 2 provides a more detailed description.

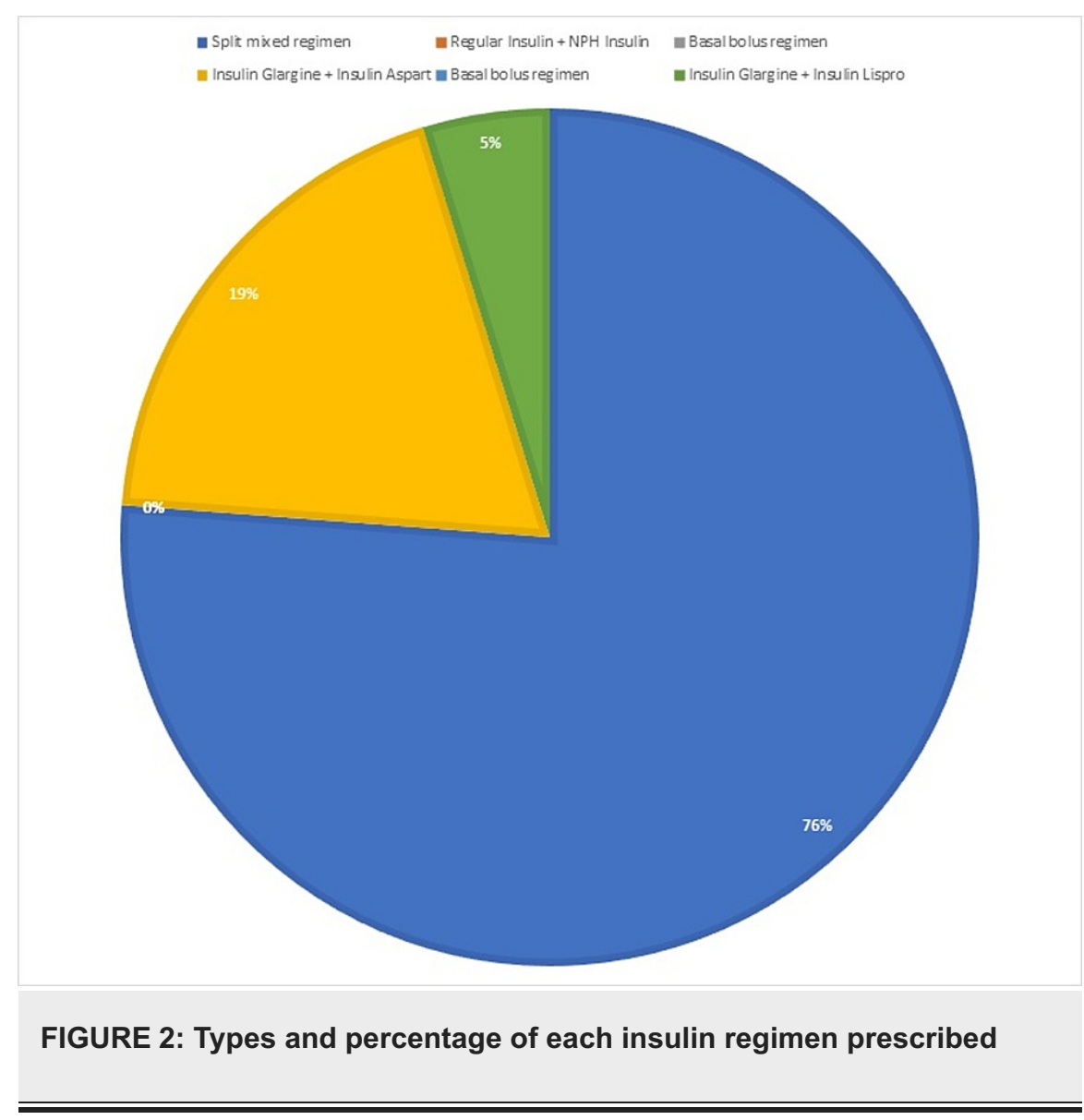

The percentage of the study population who were prescribed monotherapy was 40.49 , of which metformin in 233 (38\%) of patients was the most commonly prescribed drug followed by glibenclamide as shown in Figure 3. Metformin + glibenclamide was the most commonly prescribed combination in 201 (33.5\%) of patients followed by metformin + glimepiride in 44 (7.33\%) of patients others combinations are described in Figure 3. 


\section{Cureus}

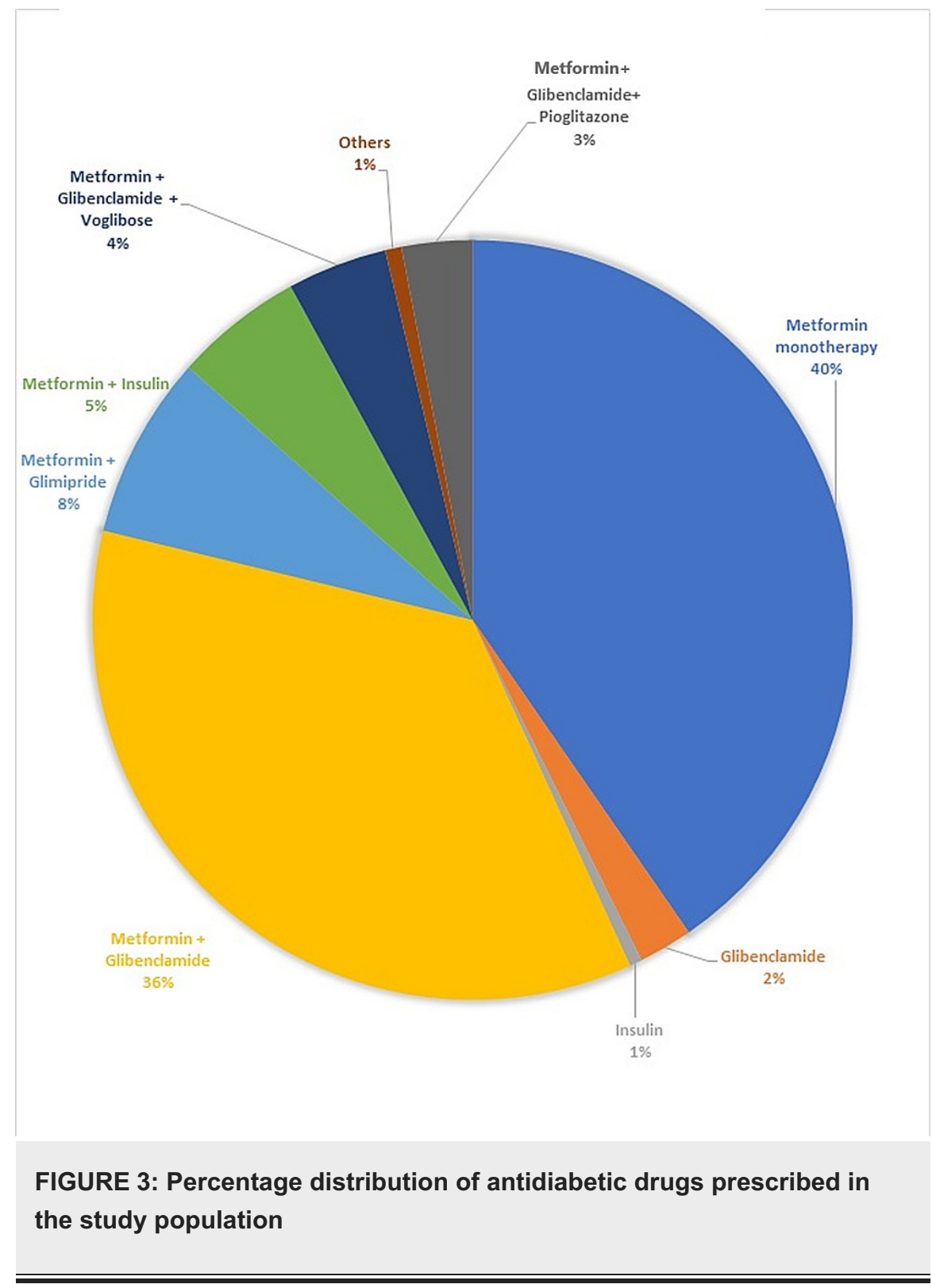

The most commonly prescribed drug for the comorbid condition was aspirin in 431 (71.83\%) patients followed by enalapril for hypertension in 307 (51.16\%) patients. Other drugs and their distributions are elaborated in Figure 4. 


\section{Cureus}

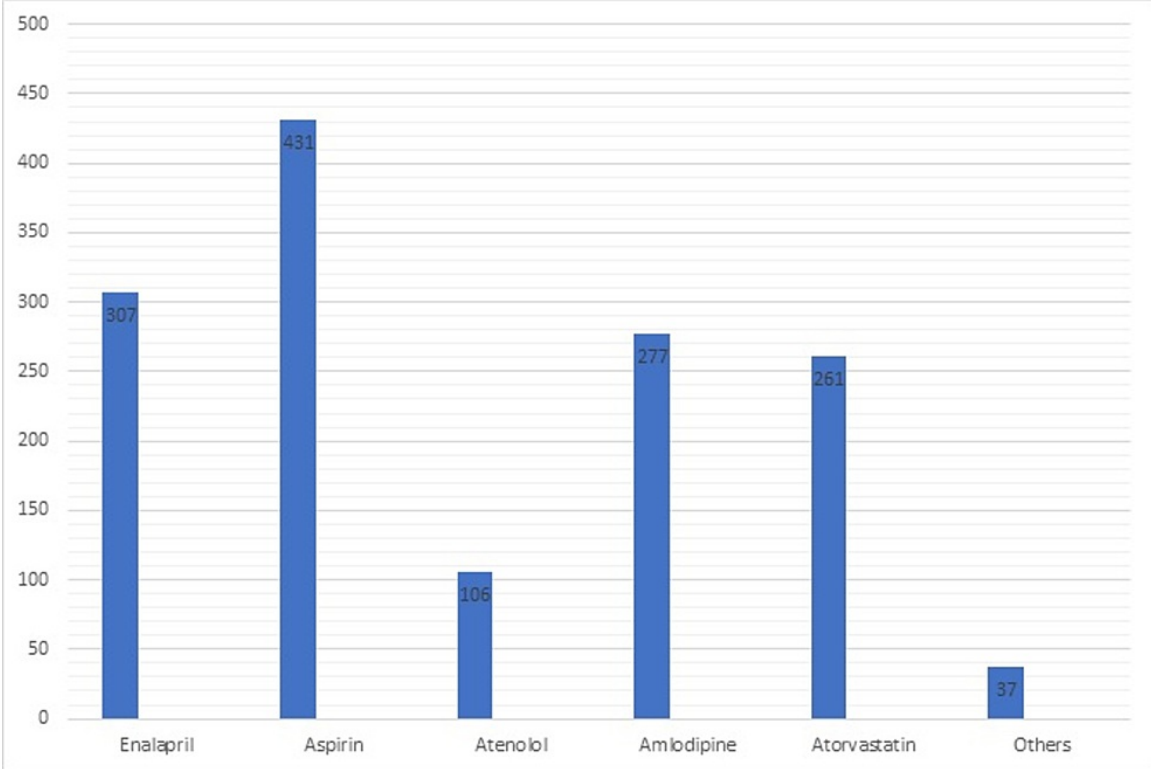

FIGURE 4: Distribution of drugs in comorbid conditions prescribed along with antidiabetics in patients

Analysis of prescription patterns according to the WHO drug use indicators

Table 2 shows the analysis of prescription patterns according to the WHO drug use indicators.

\section{Parameter}

The average number of drugs per prescription

The percentage of drugs prescribed by generic name

The average number of antidiabetic drugs per prescription is

The percentage of antidiabetic drugs prescribed from the hospital drug schedule

The percentage of antidiabetic drugs dispensed from the hospital drug schedule

The percentage utilization of scheduled drugs from the National List of Essential Medicines (NLEM) 2015[15]

TABLE 2: Analysis of prescription patterns according to the WHO drug use indicators

\section{Drug utilization patterns as per ATC/DDD Classification}

ATC/DDD categorization, PDD values, and PDD/DDD ratio of antidiabetic medications are depicted in Table 3. 


\section{Cureus}

\begin{tabular}{|c|c|c|c|c|}
\hline ATC Code & Drug & DDD & PDD & DDD/PDD \\
\hline A10BA02 & Metformin & $2 \mathrm{~g}$ & $1.54 \mathrm{~g}$ & 1.29 \\
\hline A10BB01 & Glibenclamide & $10 \mathrm{mg}$ & $10 \mathrm{mg}$ & 1 \\
\hline A10BB12 & Glimepırıde & $2 \mathrm{mg}$ & $1.08 \mathrm{mg}$ & 1.85 \\
\hline A10Bम03 & Voglibose & Not avallable on WHO-AIC site & 0.44 & - \\
\hline ATUBHOT & Sitaggilintin & $0.1 \mathrm{~g}$ & $0.06 \mathrm{~g}$ & 1.66 \\
\hline A10BG03 & Pioglitazone & $30 \mathrm{mg}$ & $30 \mathrm{mg}$ & 1 \\
\hline A10AD30 & Premixed insulin (regular insulin $+\mathrm{NPH}$ ) & 400 & $47.8 \mathrm{U}$ & 0.83 \\
\hline A10AE04 & Insulin glargine & 400 & $24.41 \mathrm{U}$ & 1.63 \\
\hline A10AB04 & Insulin lispro & $40 \mathrm{U}$ & $28 \mathrm{U}$ & 1.42 \\
\hline A10AB05 & Insulin aspart & $40 \mathrm{U}$ & $33 \mathrm{U}$ & 1.21 \\
\hline
\end{tabular}

TABLE 3: ATC/DDD classification, PDD values, and PDD/DDD ratio of antidiabetic drugs prescribed

DDD: defined daily dose, PDD: prescribed daily dose, ATC: anatomical therapeutic classification, NPH: neutral protamine Hagedorn.

\section{Cost analysis}

The average cost per prescription was USD 3.36 out of which, the cost borne by the hospital was USD 0.81 and that borne by the patient was found to be USD 2.55 . Around $87.72 \%$ of the cost per prescription was due to the antidiabetics prescribed. Table 4 below summarizes the cost analyses of the drugs.

\begin{tabular}{|c|c|c|c|c|c|c|}
\hline \multirow{2}{*}{ Drugs } & \multirow{2}{*}{$\begin{array}{l}\text { Dose per tablet } \\
\text { (mg) }\end{array}$} & \multicolumn{2}{|c|}{$\begin{array}{l}\text { Price per } 10 \text { tables/capsules in } \\
\text { USD }\end{array}$} & \multicolumn{2}{|c|}{$\begin{array}{l}\text { Average monthly cost } \\
\text { USD }\end{array}$} & \multirow{2}{*}{$\begin{array}{l}\text { Cost index } \\
(x / y)\end{array}$} \\
\hline & & Minimum (y) & Maximum (x) & Minimum & Maximum & \\
\hline Metformin & 500 & 0.145 & 0.337 & 0.870 & 2.022 & 2.32 \\
\hline Glibenclamide & 5 & 0.112 & 0.385 & 0.336 & 1.115 & 3.43 \\
\hline Glimepiride & 1 & 0.403 & 0.604 & 1.209 & 1.812 & 1.49 \\
\hline Voglibose & 0.3 & 1.209 & 2.418 & 10.881 & 21.762 & 2.00 \\
\hline Sitagliptin & 500 & 1.370 & 3.103 & 8.220 & 18.618 & 2.26 \\
\hline \multirow[t]{2}{*}{ Pioglitazone } & 15 & 0.604 & 0.725 & 1.812 & 2.175 & 1.20 \\
\hline & Dose (IU/mL) & \multicolumn{5}{|c|}{ Price per $100 \mathrm{IU}$ in USD } \\
\hline $\begin{array}{l}\text { Premix insulin (regular insulin + } \\
\mathrm{NPH} \text { ) }\end{array}$ & 100 & 2.471 & 3.936 & 37.065 & 59.04 & 1.22 \\
\hline Insulin glargine & 100 & 1.961 & 5.964 & 5.883 & 17.892 & 3.04 \\
\hline Insulin aspart & 100 & 1.873 & 5.642 & 6.742 & 20.311 & 1.87 \\
\hline Insulin lispro & 100 & 2.418 & 3.895 & 5.077 & 8.179 & 1.61 \\
\hline
\end{tabular}

TABLE 4: Cost analyzes of drugs prescribed to sample of patient attending tertiary care hospital

IU: international unit, USD: United States dollar, NPH: neutral protamine Hagedorn.

\section{Discussion}

Diabetes mellitus (DM) is a rising public health concern in developing countries. Several anti-diabetic drug utilization studies have been published in the healthcare setting from various parts of the world that can aid the rational drug use in patients with diabetes $[17,18]$. This study has concentrated on trends in anti-diabetic 
medication prescription and usage. Drug utilization study is important in clinical practice because it serves as the foundation for implementing changes to drug dispensing policies at the local and national levels. Also, since it helps in developing strategies to utilize health resources most efficiently, it is particularly needed in a developing economy like India where $72 \%$ of all health care burden is borne by the patients [19].

In our study, we observed that glibenclamide and pioglitazone had a PDD/DDD ratio of 1 . Whereas glimepiride, metformin, sitagliptin, insulin glargine, insulin lispro, and insulin aspart had ratios higher than 1 and premixed insulin had a ratio less than 1 . When the PDD/DDD ratio is less than or higher than one, it may suggest inadequate use or overuse of drugs, respectively. However, it is important to keep in mind that the PDD may vary depending on the patient and disease variables. PDDs may also vary significantly across nations; for example, PDDs are often lower in Asian people than in Caucasian ones. Additionally, the DDDs acquired from the WHO ATC/DDD website are applicable to moderately severe diseases and are based on worldwide data. As a result, the WHO encourages nations to compile their own DDD list using local data. Our study is contributing to this data, particularly for India.

We found that premixed insulin is underutilized in our settings. In contrast to this, Kalra et al. found in a review that premixed insulin is the most commonly prescribed and used insulin in Asia [20]. This may be attributable to the fact that physicians often have a difficult task in evaluating the contradictory recommendations and deciding which to adopt between basal and premixed insulin [20]. However, the present study justifies the need for prescribing more premixed insulin. Additionally, the present study included individuals in the elderly age range, who may have a preference for non-insulin regimens, resulting in underutilization of premixed insulin.

Pioglitazone is utilized optimally, which may be attributable to a preference for oral hypoglycemic regimes over insulin by patients. It is not overutilized considering its adverse effects.

Metformin alone and metformin combination was the most commonly prescribed anti-diabetic drug in the present study, in line with Orlando and coworkers [21], and Das et al. [22]. They also found that metformin was the most prescribed drug during their study. Interestingly, our results are contrasting to Ramesh and coworkers [23], Chiang et al. [24], and Al Khaja et al. [25], wherein sulfonylureas were the commonly prescribed anti-diabetic drug. This might be attributed to variations in the age groups studied in these studies. In our study, among the second-generation sulfonylureas, glibenclamide was the most commonly prescribed along with metformin which is in line with a study from Nigeria by Jimoh et al. [26]. The fact that metformin was the most prescribed drug complies with its endorsement as the preferred anti-diabetic agent by current clinical guidelines, for instance, the guidelines of the American Diabetic Association (ADA) [27].

This study was conducted in the geriatric department of a tertiary care institution, where the consultants are specialists. In many areas of India, however, diabetes patients are managed by general practitioners. When these physicians are confronted in such situations, the phenomenon of "clinical inertia" is evident. It is referred to as "A consultation in which a change in treatment based on a diabetes-related variable was indicated but did not occur” [28,29]. This leads to inappropriate prescribing and improper use of these medications. To avoid this, government entities must develop and strictly enforce policies. While our research uncovered both the patterns of under- and overuse of anti-diabetic medications, such data may be utilized by government and non-government organizations to develop policies and recommendations to reinforce the appropriate use of these medications. While it is not feasible for countries like India to afford specialists at every level of the healthcare system, it may be mandated for existing healthcare personnel to be trained in order to ensure appropriate medication use, especially for the care of chronic diseases like diabetes.

According to intercontinental marketing service (IMS) statistics, the most often used categories of drugs globally are cardiovascular drugs, which are frequently co-prescribed with anti-diabetic drugs due to the association between cardiovascular illnesses and diabetes [30]. Comorbidities such as hypertension in diabetics make it more difficult to prevent multiple medication usage; as a result, diabetics are more prone to polypharmacy and, in some cases, irrational prescriptions.

While evaluating the rationality, dose strength, and dose schedule that were mentioned in all prescriptions were studied. There was no prescription in which banned drug formulation was prescribed. For instance, pioglitazone which has a black box warning is used in $2.83 \%$ of prescriptions which is relatively low. Blood sugar levels were available for all the prescriptions studied. Patients were advised monotherapy as initial therapy and advised dietary restrictions, exercise, and advised eye, cardiovascular, and neurological checkup, which was in adherence with ADA guidelines [27]. This may be attributed to the fact that the study setting is a tertiary care facility, guidelines were followed, which may not be the case in every hospital in the country. Further studies are needed to assess current treatment patterns for good practice and quality of service.

In our study, around $87.72 \%$ of the cost per prescription was due to the antidiabetics prescribed. The reason behind this is expensive newer antidiabetic drugs and different preparations of insulin. The costs of diabetes affect everyone, everywhere, but it is not only a financial problem. Unquantifiable costs (pain, inconvenience, anxiety, and overall poorer quality of life, for example) have also been shown to have a significant effect on the lives of patients and their families [31]. It has also been observed that doctors have suboptimal awareness of the costs of the drug. The situation can be improved if drug cost is given greater emphasis during the medical training program of doctors [32]. A mention of drug cost is also required in 
medical literature and drug advertisement. Either cheaper brands with better efficacy or drugs, in general, should be prescribed as far as possible to reduce the cost of treatment for the patient. In a few instances, pharmaceutical companies use their clout to persuade physicians to prescribe costly medicines, resulting in higher-than-usual prescription costs for consumers.

This study has reported the utilization pattern of antidiabetic drugs in the geriatric population and also provided the baseline data regarding the prescribing patterns in diabetic patients. Since diabetes is a common disorder in the geriatric age group, the prescription cost is one of the major reasons for nonadherence to drug therapy. There is a need to prescribe cheaper alternatives for these types of patients for good glycemic control. This study has opened the door to more research in this field.

\section{Strengths and limitations}

Because the study was conducted in a government hospital, there may be a sampling bias since the patients who arrived here are usually from a low socioeconomic class. The population in our study was the elderly age group, hence the actual drug usage by the entire population could not be identified, and these data cannot be extrapolated for the entire population. Additionally, we were unable to evaluate patient compliance since patients were not interviewed in person. A more comprehensive study is warranted. Because of the present study design, we faced certain limitations which could be avoided with another well-designed prospective study.

The study's sample size was adequate. Since we used the EMR, Hawthorne bias was obviated. EMR is a component of the national surveillance system making the gathered data more reliable and accurate.

\section{Conclusions}

On the whole, the principles of rational prescription were followed in accordance with the different WHO drug usage indicators. Many of the drugs prescribed by generic name were supplied from hospital pharmacy thus reducing the financial burden of the patient to some extent. The incidence of poly-pharmacy is relatively high, suggestive of irrational prescribing; but polypharmacy is quite relevant in geriatric diabetic patients because diabetes is associated with various concurrent diseases and their complications. Apart from this, drugs prescribed by generic names were also high, therefore drug use in this setup is quite rational.

We would like to make the following suggestions: (i) the use of premixed insulin was found to be good but further need to increase premixed insulin in hospital drug schedules; (ii) continue the use of metformin adhering to the ADA guidelines; (iii) need to increase newer expensive antidiabetic drugs in the hospital drug schedule and pharmacy in order to relieve the financial recommendation on the patients; (iv) the practice of prescribing glibenclamide and pioglitazone should be continued.

\section{Additional Information \\ Disclosures}

Human subjects: Consent was obtained or waived by all participants in this study. Institutional Ethics Committee, Grant Government Medical College and Sir JJ Group of Hospitals, Byculla, Mumbai, India issued approval IEC/Pharm/445/2014. Animal subjects: All authors have confirmed that this study did not involve animal subjects or tissue. Conflicts of interest: In compliance with the ICMJE uniform disclosure form, all authors declare the following: Payment/services info: All authors have declared that no financial support was received from any organization for the submitted work. Financial relationships: All authors have declared that they have no financial relationships at present or within the previous three years with any organizations that might have an interest in the submitted work. Other relationships: All authors have declared that there are no other relationships or activities that could appear to have influenced the submitted work.

\section{References}

1. Diabetes - World Health Organization . (2021). Accessed: August 18, 2021: https://www.who.int/healthtopics/diabetes\#tab=tab 1 .

2. Anjana RM, Deepa M, Pradeepa R, et al.: Prevalence of diabetes and prediabetes in 15 states of India: results from the ICMR-INDIAB population-based cross-sectional study. Lancet Diabetes Endocrinol. 2017, 5:58596. 10.1016/S2213-8587(17)30174-2

3. Al-Musawe L, Martins AP, Raposo JF, Torre C: The association between polypharmacy and adverse health consequences in elderly type 2 diabetes mellitus patients: a systematic review and meta-analysis. Diabetes Res Clin Pract. 2019, 155:107804. 10.1016/j.diabres.2019.107804

4. Drug utilization - an overview. (2019). Accessed: June 18, 2021: https://www.sciencedirect.com/topics/pharmacology-toxicology-and-pharmaceutical-science/drugutilization.

5. India State-Level Disease Burden Initiative Diabetes Collaborators: The increasing burden of diabetes and variations among the states of India: the Global Burden of Disease Study 1990-2016. Lancet Glob Health. 2018, 6:e1352-62. 10.1016/S2214-109X(18)30387-5

6. Mathers CD, Loncar D: Projections of global mortality and burden of disease from 2002 to 2030 . PLoS Med. 2006, 3:e442. 10.1371/journal.pmed.0030442

7. What are the main causes of population aging and its consequences on the provision of healthcare? . (2018). Accessed: May 26, 2021: 
https://www.researchgate.net/publication/332303878_What_are_the_main_causes_of_population_aging_and_its_consequence:

8. Sultana G, Kapur P, Aqil M, Alam MS, Pillai KK: Drug utilization of oral hypoglycemic agents in a university teaching hospital in India. J Clin Pharm Ther. 2010, 35:267-77. 10.1111/j.1365-2710.2009.01080.x

9. How to investigate drug use in health facilities selected drug use indicators . (1993). Accessed: May 27, 2021: https://www.scirp.org/reference/ReferencesPapers.aspx.

10. von Elm E, Altman DG, Egger M, Pocock SJ, Gøtzsche PC, Vandenbroucke JP: Strengthening the reporting of observational studies in epidemiology (STROBE) statement: guidelines for reporting observational studies. BMJ. 2007, 335:806-8. 10.1136/bmj.39335.541782.AD

11. Introduction to drug utilization research. (2003). Accessed: August 27, 2021: https://www.whocc.no/filearchive/publications/drug_utilization_research.pdf.

12. WHOCC - Updates included in the ATC/DDD index . (2021). Accessed: May 27, 2021: https://www.whocc.no/atc_ddd_index/updates_included_in_the_atc_ddd_index/.

13. Defined daily dose (DDD). (2017). Accessed: July 26, 2021: https://www.who.int/tools/atc-dddtoolkit/about-ddd.

14. Drug price of all the brand names. (2017). Accessed: July 25, 2021: https://www.medindia.net/drugprice/index.asp.

15. National list of essential medicines 2015. (2015). Accessed: May 27, 2021: https://www.nppaindia.nic.in/en/utilities/national-list-of-essential-medicines/nlem-2015/.

16. WHO model lists of essential medicines. (2017). Accessed: July 26, 2021: https://www.who.int/groups/expert-committee-on-selection-and-use-of-essential-medicines/essentialmedicines-lists.

17. Bang C, Mortensen MB, Lauridsen KG, Bruun JM: Trends in antidiabetic drug utilization and expenditure in Denmark: a 22-year nationwide study. Diabetes Obes Metab. 2020, 22:167-72. 10.1111/dom.13877

18. Hankó B, Tukarcs E, Kumli P, Vincze Z: Antidiabetic drug utilization in hungary. Pharm World Sci. 2005, 27:263-5. 10.1007/s11096-004-5804-1

19. Mittal N, Mittal R, Singh I, Shafiq N, Malhotra S: Drug utilisation study in a tertiary care center: recommendations for improving hospital drug dispensing policies. Indian J Pharm Sci. 2014, 76:308-14.

20. Kalra S, Balhara YP, Sahay BK, Ganapathy B, Das AK: Why is premixed insulin the preferred insulin? Novel answers to a decade-old question. J Assoc Physicians India. 2013, 61:9-11.

21. Moreno Juste A, Menditto E, Orlando V, et al.: Treatment patterns of diabetes in Italy: a population-based study. Front Pharmacol. 2019, 10:870. 10.3389/fphar.2019.00870

22. Das P, Prasad Das B, Prasad Rauniar G, Kumar Roy R, Kumar Sharma S: Drug utilization pattern and effectiveness analysis in diabetes mellitus at a tertiary care centre in Eastern Nepal. J Physiol Pharmacol. 2011, 55:272-80

23. Kulkarni SV, Meenatchi S, Reeta R, Ramesh R, Srinivasan AR, Lenin C: Association of glycemic status with bone turnover markers in type 2 diabetes mellitus. Int J Appl Basic Med Res. 2017, 7:247-51. 10.4103/ijabmr.IJABMR 3517

24. Chiang CW, Chiu HF, Chen CY, Wu HL, Yang CY: Trends in the use of oral antidiabetic drugs by outpatients in Taiwan: 1997-2003. J Clin Pharm Ther. 2006, 31:73-82. 10.1111/j.1365-2710.2006.00705.x

25. Al Khaja KA, Sequeira RP, Damanhori AH: Comparison of the quality of diabetes care in primary care diabetic clinics and general practice clinics. Diabetes Res Clin Pract. 2005, 70:174-82. 10.1016/j.diabres.2005.03.029

26. Jimoh AO, Sabir AA, Chika A, Sani Z: Pattern of antidiabetic drugs use in a diabetic outpatient clinic of a tertiary health institution in Sokoto, North-western Nigeria. J Med Sci. 2011, 11:241-5. 10.3923/JMS.2011.241.245

27. Medication and treatments | ADA. (2021). Accessed: July 25, 2021: https://www.diabetes.org/healthyliving/medication-treatments.

28. Andreozzi F, Candido R, Corrao S, et al.: Clinical inertia is the enemy of therapeutic success in the management of diabetes and its complications: a narrative literature review. Diabetol Metab Syndr. 2020, 12:52. 10.1186/s13098-020-00559-7

29. Marjanović M, Vrdoljak D, Bralić Lang V, et al.: Clinical inertia in type 2 diabetes patients in primary health care clinics in central Bosnia. Med Sci Monit. 2018, 24:8141-9. 10.12659/MSM.911286

30. Vijayakumar S, Sasikala M, Mohammed Saleem TS, Gauthaman K: Prevalence of diabetes in Sikkim and Darjeeling district of west Bengal and role of risk factor associated with it: a preliminary survey. IJCP. 2008, $1: 36-40$.

31. Riddle MC, Herman WH: The cost of diabetes cared an elephant in the room . Diabetes Care. 2018, 41:92932. 10.2337/dci18-0012

32. Allan GM, Lexchin J, Wiebe N: Physician awareness of drug cost: a systematic review . PLoS Med. 2007, 4:e283. 10.1371/journal.pmed.0040283 